Article

\title{
Spatial-Temporal Characteristics of Cultivated Land Use Efficiency in Major Function-Oriented Zones: A Case Study of Zhejiang Province, China
}

\author{
Chaozheng Zhang ${ }^{1,+}{ }^{\oplus}$, Yangyue $\mathrm{Su}^{2,+}$, Gangqiao Yang ${ }^{1, *}$, Danling Chen ${ }^{3}$ and Rongxuan Yang ${ }^{1}$ \\ 1 College of Public Administration, Huazhong Agricultural University, Wuhan 430070, China; \\ weirdo08@ad.unc.edu (C.Z.); yanligao@ad.unc.edu (R.Y.) \\ 2 School of Economics and Management, Tongji University, Shanghai 200092, China; 1710260@tongji.edu.cn \\ 3 College of Public Administration, Huazhong University of Science and Technology, Wuhan 430074, China; \\ danlingc@hust.edu.cn \\ * Correspondence: ygq@mail.hzau.edu.cn \\ + Both authors contributed equally to this work and should be considered co-first authors.
}

Received: 28 February 2020; Accepted: 7 April 2020; Published: 10 April 2020

\begin{abstract}
Promoting cultivated land use efficiency (CLUE) coordinated development in various major function-oriented zones is a measure to deal with unbalanced development of territorial space in China. Taking the optimized development, key development, agricultural production, ecological function, and ecological economic zones of Zhejiang province as research objects, this study incorporated agricultural carbon emission into the measurement framework of CLUE and analyzed the regional disparity and the convergence of CLUE from 2008 to 2017, using slack-based measure model (SBM), the Theil index, and convergence theory. The main results are as follows: (1) The CLUE value that considered agricultural carbon emissions was lower than the CLUE value that did not consider agricultural carbon emissions; thus, agricultural carbon emissions had a negative effect on CLUE. (2) The CLUE value of the five major function-oriented zones showed an increasing trend; after ranking the CLUE value, the CLUE of the optimized development zones was the highest, followed by the ecological function, ecological economic, and key development zones, and that of the agricultural production zones was the lowest, indicating significant regional disparity. (3) The overall disparity of CLUE presented an upward trend, and the within-regional disparity is the main source of the overall disparity. (4) Neither $\sigma$ convergence nor absolute $\beta$ convergence occurred in the CLUE of the five major function-oriented zones, but conditional $\beta$ convergence occurred among the optimized development and ecological economic zones. Although the planning of major function-oriented zones reflects the regional disparity and convergence of CLUE to some extent, the CLUE under the control of major function-oriented zones is not consistent with the function positioning.
\end{abstract}

Keywords: cultivated land use efficiency; agricultural carbon emission; major function-oriented zones; regional disparity; regional convergence

\section{Introduction}

The State Council of China issued the "National Plan for Major Function-Oriented Zones" in 2010 [1], which divided the land into four categories: Optimized, key, restricted, and forbidden development zones, and the restricted development zones were further sub-categorized into ecological function and agricultural production zones. The major function-oriented zones fall under regional planning based on existing development intensity, resource and environment carrying capacity, and future development potential, and perform overall planning for future land use, economic layout, population distribution, and urbanization patterns, which takes the administrative county 
as the basic unit [2,3]. Compared with traditional regional planning, the ultimate goal of the major function-oriented zones is to develop a spatial development pattern in which economy, population, environment, and resources are coordinated rather than economic development [1]. Due to different natural resource endowments and socioeconomic development levels [4], there is a significant difference in CLUE among different major function-oriented zones. Promoting CLUE-coordinated development in various major function-oriented zones has become an important way to deal with unbalanced development of territorial space. Therefore, analysis of CLUE in various major function-oriented zones is of great importance for promoting harmonious and sustainable land development patterns, as well as formulating targeted and effective cultivated land use policies.

Cultivated land is an essential material basis for human survival and development. However, previous studies on cultivated land are concentrated on abandonment, protection, conversion, consolidation, quality, and fragmentation [5-9]. Additionally, studies related to land use efficiency are limited to urban and industrial lands $[10,11]$. By contrast, little attention has been paid to CLUE. CLUE is a key indicator that is commonly used to reflect the rationality of factor input in the process of land use [12], and the realization of land value in agricultural production [13]. Although the evaluation of CLUE has gradually attracted attention from both governments and scholars since it was introduced by Kendall [14], there are no widely-accepted indicator systems and evaluation methods of CLUE. Some scholars employed the crop output value [15], land equivalent ratio [16], multiple cropping index [17], and area*time equivalent ratio [18] as indicators for CLUE, which essentially measured the single-factor efficiency. As a matter of fact, cultivated land must be combined with fertilizer, pesticides, labor force, agricultural film, and other input factors to facilitate agricultural production [19]. In that regard, data envelopment analysis (DEA) developed by Charnes and Cooper [20] can be used to evaluate the relative efficiency of decision-making units (DMUs) with multiple inputs and one output. However, traditional DEA models such as BBC and CCR are radical and oriented; their drawbacks are that inputs and output are assumed to undergo equal proportional changes, and remaining slacks in inputs and output are not accounted for in the CLUE score [21], which ultimately results in a biased estimation. In an attempt to define inefficiency based on the slacks, the SBM model was first proposed by Tone and extended to deal with undesirable outputs [21,22]. The SBM model is characterized as non-radial and non-oriented, which treats slacks directly in the objective function. Compared with traditional DEA models, the SBM model can better solve the slacks caused by radial and oriented selection, as well as reflect the essence of CLUE.

The use of cultivated land has the dual effect of providing agricultural products and causing environmental pollution $[23,24]$. Therefore, cultivated land use should not only maximize the desirable outputs, but also minimize the undesirable outputs. However, most studies related to CLUE only emphasized the desirable outputs while ignoring the undesirable outputs [23-25], inevitably leading to biased results. Nevertheless, some scholars have tried to include undesirable outputs into consideration when constructing the indicators system of CLUE. For instance, Xie et al. [23] selected agricultural non-point source pollution as an undesirable output when evaluating the cultivated land use eco-efficiency of China; Hou et al. [26] considered phosphorus and nitrogen losses from fertilizers to characterize the agricultural non-point source pollution. However, the scope of agricultural non-point source pollution is not comprehensive. Although agricultural carbon emissions cover a wider range than agricultural non-point sources and are easier to quantify, only a few scholars have tried to take agricultural carbon emissions into consideration when evaluating the CLUE. For example, Kuang et al. [27] included agricultural carbon emission in the measurement framework of CLUE when analyzing the provincial CLUE in China; Xie et al. [28] comprehensively selected agricultural carbon emissions and non-point source pollution when analyzing the CLUE of China's main grain-producing areas. However, they selected the cultivated land as one of the input indicators, and they essentially measured the total factor productivity, not the CLUE. In addition, these studies are mainly based on traditional administrative divisions such as national, provincial, or basin scales, and lack consideration of regional function positioning. As far as we know, almost no studies have evaluated and analyzed 
the CLUE in various major function-oriented zones. Given the huge disparity in natural resource endowments and socioeconomic development levels among different regions, it is more meaningful to study the CLUE based on the major function-oriented zones rather than the traditional administrative divisions. Thus, it is quite necessary to evaluate the CLUE of various major function-oriented zones, which will provide a scientific bias for formulating regionally-differentiated cultivated land use policies in China.

With the expanding regional imbalance in China, it is of great importance to measure the CLUE in various major function-oriented zones, along with examining whether the regional disparity and convergence in the presence of multidimensional heterogeneity exist for CLUE. If the regional disparity and convergence exist, we wonder how they perform in various major function-oriented zones and in different periods, i.e., the optimized development zones vs. the key development zones and the periods of 2008-2012 vs. 2013-2017. Thus, the contribution of this study mainly concentrates on the following two aspects. First, the SBM model that considers undesirable outputs as well as the CCR model that does not consider undesirable outputs are employed to measure the CLUE of Zhejiang province and its various major function-oriented zones from 2008 to 2017, which enables a more accurate assessment of CLUE. Second, the Theil index and convergence theory are adopted to analyze the dynamic evolution of regional disparity and convergence of CLUE in various major function-oriented zones.

\section{Materials and Methods}

\subsection{Study Area}

Zhejiang province $\left(27^{\circ} 01^{\prime} \mathrm{N}-31^{\circ} 11^{\prime} \mathrm{N}, 118^{\circ} 01^{\prime} \mathrm{E}-123^{\circ} 08^{\prime}\right)$ is located in the Southeast coast of China and extends over an area of $101,800 \mathrm{~km}^{2}$, equivalent to $1.06 \%$ of the national territory, which makes the province one of the smallest in China (see Figure 1). It features a varied and complicated topography: Mountains and hills account for $70.4 \%$ of the total area; plains and basins make up $23.2 \%$; $6.4 \%$ is water area composed of rivers and lakes; and only $19,820 \mathrm{~km}^{2}$ is cultivated land [29]. That is the reason why the province is said to have $70 \%$ of its land as hills, $10 \%$ as water area, and $20 \%$ as cultivated land. With a total population of 56.57 million as of 2017, Zhejiang is one of the provinces with the smallest per-capita cultivated land area in China [29]. After the launch of the reform and opening-up policy in 1978, Zhejiang grew to be considered one of the wealthiest and most developed provinces, ranking fourth in GDP nationally and fifth by GDP per capita, with a nominal GDP of 5.62 trillion RMB and per capita GDP of 92,000 RMB as of 2017 [30]. The widespread conversion from cultivated land to construction land has aggravated the contraction between cultivated land and socioeconomic development. In August 2013, the People's Government of Zhejiang Province issued "the Planning of the Major Function-Oriented Zones in Zhejiang Province", which was designed by the national- and provincial-level and categorized the land into four categories [31]. The restricted development zones were further sub-categorized into agricultural production, ecological function, and ecological economic zones (Figures 1 and 2). The forbidden development zones are embedded within the optimized, key, and restricted development zones, and the area of the forbidden development zones is relatively small [32]; thus it is not included as a research object in this study. More details can be found in the Appendix A (Tables A1-A3). 


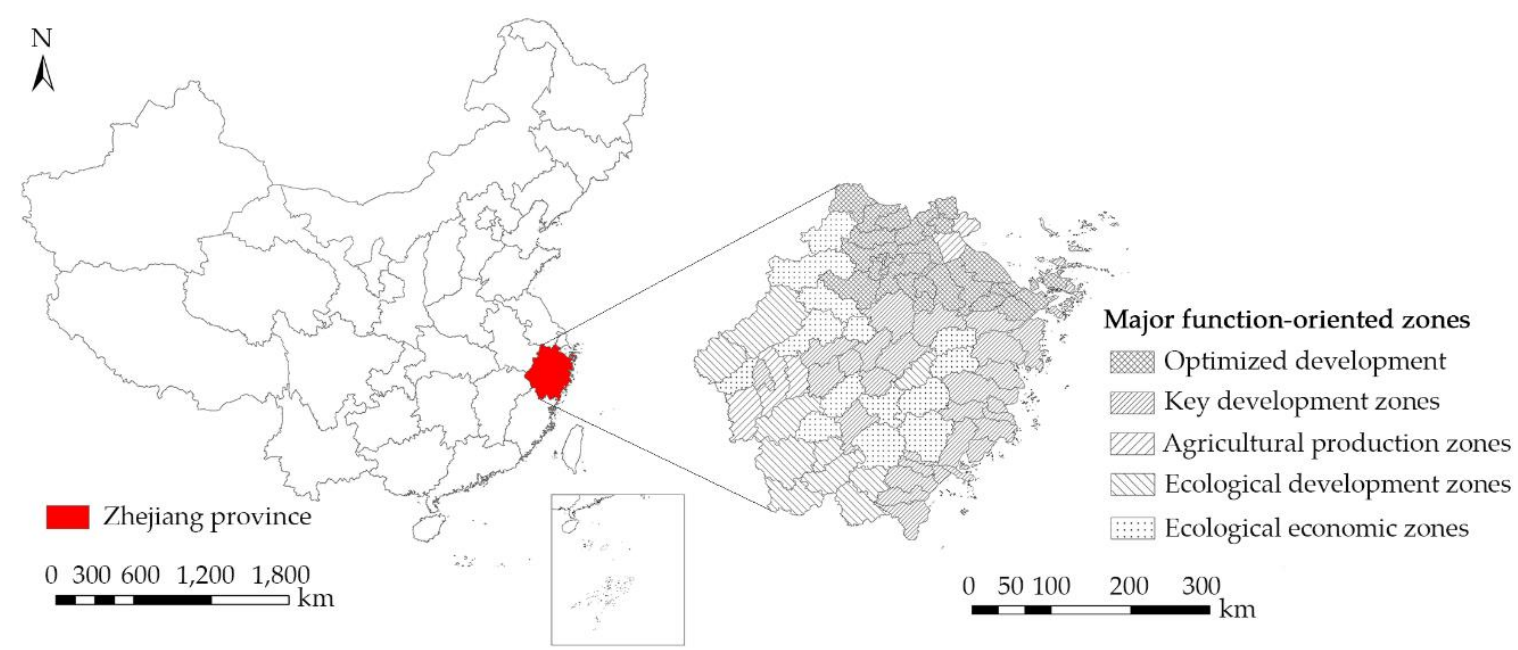

Figure 1. Spatial distribution of the five major function-oriented zones in Zhejiang province.

Optimized development zones: These cover covers an area of $16,317 \mathrm{~km}^{2}$, accounting for $16 \%$ of the province's land area. It mainly distributed in the Hangzhou Bay area and the South wing of the Yangtze River Delta.

Key development zones: These cover an area of $17,271 \mathrm{~km}^{2}$, accounting for $17 \%$ of the province's land area. They are mainly distributed in the coastal plain area, zhoushan archipelago new area, and in inland hilly basin area.

Agricultural production zones: These cover an area of $5,429 \mathrm{~km}^{2}$, accounting for $5.3 \%$ of the province's land area. They are distributed in the national grain-producing counties, including Haiyan county and Pinghu city in Jiaxing city, Qujiang district, Jiangshan city and Longyou city in Quzhou city.

Key development zones: These cover an area of $21,109 \mathrm{~km}^{2}$, accounting for $20.7 \%$ of the province's land area. They are mainly distributed in the mountainous hills in Western and Southern Zhejiang, and the source of Jianghe river in central Zhejiang.

Ecological economic zones: These cover an area of $41,674 \mathrm{~km}^{2}$, accounting for $41 \%$ of the province's land area. These are mainly distributed on the island in the Eastern Zhejiang, and the hills of the Western, Southern and central-Eastern Zhejiang.

Forbidden development zones: These cover an area of $9,724 \mathrm{~km}^{2}$, accounting for $9.6 \%$ of the province's land area. These are mainly distributed in the optimized, key, and restricted development zones. Therefore, these are not included as research objects in this study, and their distribution is not shown in Figure 1.

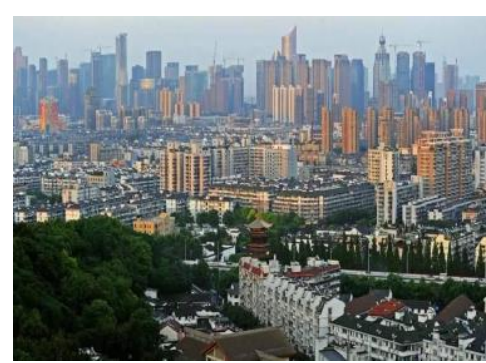

(a)

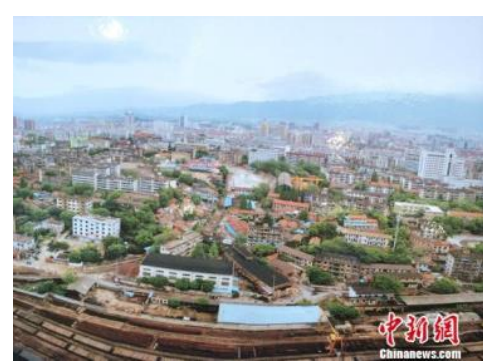

(b)

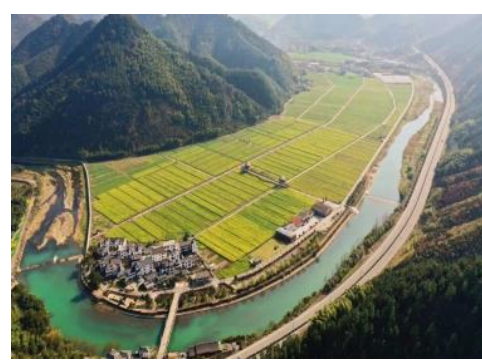

(c)

Figure 2. Cont. 


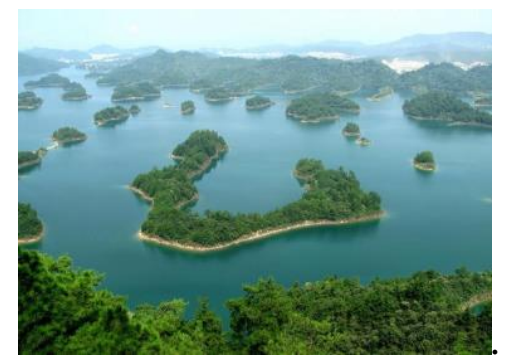

(d)

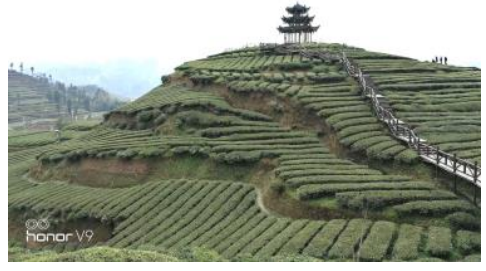

(e)

Figure 2. Representative photos of the five major function-oriented zones: (a) optimized development zones, retrieved from: mt.sohu.com; (b) key development zones, retrieved from: news.ifeng.com; (c) agricultural production zones, retrieved from: www.sohu.com; (d) ecological function zones, retrieved from: you.ctrip.com; (e) ecological function zones, source: Author's own photograph.

\subsection{Methods}

\subsubsection{SBM Model with Undesirable Output}

Supposing that the cultivated land use system has $n$ homogeneous DMUs, each DMUs use $m$ inputs to produce $s_{1}$ desirable outputs and $s_{2}$ undesirable outputs [20,21]. The three factors can be represented by three vectors: $x \in R^{m}, y^{g} \in R^{s_{1}}$ and $y^{b} \in R^{s_{2}}$, respectively. The matrices $X, Y^{g}, Y^{b}$ can be defined as follows: $X=\left[x_{1}, x_{2}, \cdots, x_{n}\right], Y^{g}=\left[y_{1}^{g}, y_{2}^{g}, \cdots, y_{n}^{g}\right], Y^{b}=\left[y_{1}^{b}, y_{2}^{b}, \cdots, y_{n}^{b}\right]$, and $x_{i}>0$, $y_{i}^{g}>0, y_{i}^{b}>0$. The production possible set can be expressed as Equation (1) and the SBM model can be defined as Equation (2).

$$
\begin{gathered}
P=\left\{\left(x, y^{g}, y^{b}\right) \mid x \geq X \lambda, y^{g} \leq Y^{g} \lambda, y^{b} \geq Y^{g} \lambda, \lambda \geq 0\right\} \\
\rho^{*}=\min \frac{1-\frac{1}{m} \sum_{i=1}^{m} \frac{s_{i}^{-}}{x_{i 0}}}{1+\frac{1}{s_{1}+s_{2}}\left(\sum_{r=1}^{s_{1}} \frac{s_{r}^{g}}{y_{r 0}^{g}}+\sum_{r=1}^{s_{2}} \frac{s_{r}^{b}}{y_{r 0}^{b}}\right)} \\
\text { s.t. }\left\{\begin{array}{l}
x_{0}=X \lambda+s^{-} ; y_{0}^{g}=Y^{g} \lambda-s^{g} ; y_{0}^{b}=Y^{b} \lambda+s^{b} \\
s^{-} \geq 0 ; s^{g} \geq 0 ; s^{b} \geq 0 ; \lambda \geq 0
\end{array}\right.
\end{gathered}
$$

where $s_{i}^{-}, s_{r}^{g}$ and $s_{r}^{b}$ is slacks in inputs, desirable outputs and undesirable outputs, respectively; $\lambda$ is a non-negative vector of weights. The target function value of $\rho^{*}$ is the relative efficiency of DMUs, satisfies $0<\rho^{*} \leq 1$. If $\rho^{*}=1, s_{i}^{-}, s_{r}^{g}$ and $s_{r}^{b}$ are all zero, it means the DMUs is efficient; If $0<\rho^{*}<1, s_{i}^{-}, s_{r}^{g}$ and $s_{r}^{b}$ are non-zero, it means the DMUs is inefficient [21,22].

\subsubsection{Theil Index and Its Decomposition}

The Theil index, first proposed by Theil [32], is an important index that measures the relative extent of regional disparity. Alternatively, the Gini coefficient can also be adapted to measure regional disparity. Although the Gini coefficient is decomposable, the component terms of overall disparity are not always intuitively or mathematically appealing [33]. Compared with the Gini coefficient, the Theil index could be decomposed into between- and within-regional disparity. The former measures the disparities among different major function-oriented zones, whereas the latter is a weighted average of county disparities within each major function-oriented zone [32]. The Theil index and its decomposition can be calculated as follows:

$$
\text { Theil }_{\text {overall }}=\frac{1}{n} \sum_{i=1}^{n} \frac{\mathrm{CLUE}_{i}}{\mathrm{CLUE}_{i}} \operatorname{Ln} \frac{\mathrm{CLUE}_{i}}{\mathrm{CLUE}_{i}}
$$




$$
\begin{gathered}
\text { Theil } l_{\text {between }}=\sum_{j=1}^{k} \frac{n_{j}}{n} \frac{\mathrm{CLUE}_{j}}{\mathrm{CLUE}} \operatorname{Ln} \frac{\mathrm{CLUE}_{j}}{\mathrm{CLUE}} \\
\text { Theil }_{\text {within }}=\sum_{j=1}^{k} \frac{n_{j}}{n_{j}} \frac{\mathrm{CLUE}_{j}}{\mathrm{CLUE}_{j}} \sum_{i=1}^{n_{j}} \frac{\mathrm{CLUE}_{i j}}{\mathrm{CLUE}_{j}} \operatorname{Ln} \frac{\mathrm{CLUE}_{i j}}{\mathrm{CLUE}_{j}} \\
\text { Theil }_{\text {overall }}=\text { Theil }_{\text {between }}+\text { Theil }_{\text {within }}
\end{gathered}
$$

where Theil $l_{\text {overall }}$, Theil $l_{\text {between }}$ and Theil $l_{\text {within }}$ are overall, between-regional and within-regional disparity, respectively; $n$ and $k$ are the number of counties and major function-oriented zones, respectively; $n_{j} / n$ and $C_{L U E} / C L U E$ are the sample proportion and CLUE share of $j$-th region, respectively; $C_{2 U E} i j$ is the CLUE of $i$-th county within $j$-th region.

\subsubsection{Convergence Theory Tests}

There are three distinguished types of convergence theory: $\sigma$ convergence, absolute $\beta$ convergence, conditional $\beta$ convergence $[33,34]$. Drawing on the definition, $\sigma$ convergence examines whether the deviation of CLUE within each major function-oriented zone tends to decrease over time. Absolute $\beta$ convergence examines whether the within-regional CLUE converges to the same steady-state level. Conditional $\beta$ convergence examines whether the within-regional CLUE converges to its respective steady-state equilibrium level that is conditional on region-specific characteristics [34,35].

First, we conduct the $\sigma$ convergence test. The standard deviation and the coefficient of variation are the most frequently used measures of $\sigma$ convergence [34]. This paper first adopts the standard deviation to test whether the deviation of CLUE of each major function-oriented zone tends to decrease over time, and then uses the coefficient of variation to verify the robustness of the result. Their formulas can be expressed as follows:

$$
\begin{gathered}
S D_{t}=\sqrt{\frac{1}{n} \sum_{i=1}^{n}\left(\mathrm{CLUE}_{i}-\frac{1}{n} \sum_{i=1}^{n}\left(\mathrm{CLUE}_{i}\right)^{2}\right.} \\
C V_{t}=\sqrt{\frac{1}{n} \sum_{i=1}^{n}\left(\mathrm{CLUE}_{i}-\frac{1}{n} \sum_{i=1}^{n} \mathrm{CLUE}_{i}\right)^{2}} / \frac{1}{n} \sum_{i=1}^{n} \mathrm{CLUE}_{i}
\end{gathered}
$$

where $S D_{t}$ and $C V_{t}$ are the standard deviation and coefficient of variation of CLUE at year $t ; n$ is the number of counties. $\sigma$ convergence occurs if $S D_{t+1}<S D_{t}$ or $C V_{t+1}<C V_{t}$.

Then, we conduct the absolute $\beta$ convergence test. We divide the total period into two shorter periods using a five-year interval: 2008-2012 and 2013 - 2017, so that the estimated results can be less influenced by serial correlation and business-cycle fluctuations than in a yearly setup $[35,36]$. The classical equation of absolute $\beta$ convergence can be formulated as follows:

$$
\operatorname{Ln}\left(\mathrm{CLUE}_{i, t}\right)-\operatorname{Ln}\left(\mathrm{CLUE}_{i, t-1}\right)=\alpha+\beta \operatorname{Ln}\left(\mathrm{CLUE}_{i, t-1}\right)+\varepsilon_{i, t}
$$

where $\mathrm{CLUE}_{i, t}$ and $\mathrm{CLUE}_{i, 0}$ is the CLUE of $i$-th county at the terminal and initial stage, respectively; $T$ is the length of observation interval; $\beta$ is the parameters to be estimated. Absolute $\beta$ convergence occurs if $\beta$ is significantly negative. The convergence rate $\lambda$ and convergence time $\theta$ of the absolute $\beta$-convergence can be calculated as follows:

$$
\begin{gathered}
\lambda=\operatorname{Ln}(1+\beta T) / T \\
\theta=\operatorname{Ln}(2) / \lambda
\end{gathered}
$$

Lastly, we conduct the conditional $\beta$ convergence test. The two-way fixed effects model was adopted to examine the conditional $\beta$ convergence of CLUE. The method controls for both individual and time-fixed effects, to the extent that the method accommodates differences across counties, allows different steady-state levels for each county, and the method essentially transforms into a conditional $\beta$ 
convergence test [37]. The main advantage of the method is that the multidisciplinary and endogenous problems among variables can be explained, and the omission of control variables can be avoided.

$$
\operatorname{Ln}\left(\mathrm{CLUE}_{i, t}\right)-\operatorname{Ln}\left(\mathrm{CLUE}_{i, t-1}\right)=\alpha+\beta \operatorname{Ln}\left(\mathrm{CLUE}_{i, t-1}\right)+\varepsilon_{i, t}
$$

where $\operatorname{CLUE}_{i, t}$ and $\mathrm{CLUE}_{i, t-1}$ are the CLUE of counties at year $t$ and $t-1$, respectively; $\beta$ is the parameters to be estimated. Conditional $\beta$ convergence occurs if $\beta$ is significantly negative.

The convergence rate $\lambda$ of the absolute $\beta$ convergence can be formulated as follows:

$$
\lambda=\operatorname{Ln}(1+\beta) / T
$$

\section{Indicator Selection and Data Sources}

\subsection{Indicator Selection}

CLUE refers to the ratio of output and input per cultivated land area [14]. Based on the definition of CLUE, we suggest that input/output per cultivated land area should be considered when constructing the measurement framework of CLUE ${ }^{1}$. Based on the principles of authenticity, availability, and representativeness, eight indicators are selected to construct the measurement framework of CLUE (see Table 1). The input, desirable output, and undesirable output indicators for measuring CLUE are described as follows:

Labor force input: As the Statistical Bureau of Zhejiang Province has not reported the data pertaining to the labor force involved in cultivated land use, we converted the number of agricultural, forestry, husbandry, and fishery employees into the number of labor force employed on cultivated land. This was completed by multiplying the former with the ratio of the crop farming output value to the gross output value of agricultural, forestry, husbandry, and fishery [14,25]. Additionally, the ratio of labor force employed on cultivated land to the total sown area of farm crops was used to reflect labor force input.

Machinery input: Due to the limited data collection on the machinery power involved in cultivated land use, we converted the total power of agricultural machinery power into the machinery input. This was completed by multiplying the former with the ratio of the crop farming output value to the gross output value of agricultural, forestry, husbandry, and fishery industries [14,25].

Irrigation input: The ratio of effective irrigated area to the total sown area of farm crops was selected to present the irrigation input.

Chemical fertilizer input: The ratio of fertilizer application amount to the total sown area of farm crops was selected to reflect chemical fertilizer input.

Pesticide input: The ratio of pesticide application amount to the total sown area of farm crops was selected to present pesticide input.

Agricultural film input: The ratio of agricultural film application amount to the total sown area of farm crops was selected to reflect agricultural film input.

Desirable output: The ratio of crop farming output value to the total sown area of farm crops was selected as a desirable output, and crop farming output value was converted into 2008 constant prices.

Undesirable output: The ratio of agricultural carbon emissions to the total sown area of farm crops was selected as an undesirable output. The formula is as follows:

$$
E=\sum_{i=1}^{n} E_{i}=\sum_{i=1}^{n} T_{i} \cdot \delta_{i}
$$

1 Considering the multiple-crop index, we used the total sown area of farm crops to represent cultivated land input, instead of the total area of cultivated land. 
where $E$ is the total amount of agricultural carbon emissions; $E_{i}$ is the amount of agricultural carbon emissions from $i$-th carbon source; $T_{i}$ and $\delta_{i}$ are the consumption amount and emission coefficient of $i$-th carbon emission source, respectively (see Table 2 ).

Table 1. The indicator system of cultivated land use efficiency (CLUE).

\begin{tabular}{llllll}
\hline \multicolumn{1}{c}{ Indicators } & \multicolumn{1}{c}{ Unit } & \multicolumn{1}{c}{ Mean } & \multicolumn{1}{c}{ Std. Dev. } & \multicolumn{1}{c}{ Min } & \multicolumn{1}{c}{ Max } \\
\hline Labor force & $10^{4} \mathrm{person}^{2} 10^{3} \mathrm{hm}^{-2}$ & 0.161 & 0.133 & 0.023 & 1.092 \\
Machinery & $10^{4} \mathrm{~kW} \cdot 10^{3} \mathrm{hm}^{-2}$ & $4,621.454$ & $2,662.910$ & 745.828 & $21,006.024$ \\
Irrigation & $\%$ & 56.924 & 21.502 & 3.846 & 166.422 \\
Chemical fertilizer & $\mathrm{t} .10^{3} \mathrm{hm}^{-2}$ & 353.685 & 173.869 & 16.312 & 1931.995 \\
Pesticides & $\mathrm{t} .10^{3} \mathrm{hm}^{-2}$ & 22.927 & 14.915 & 3.831 & 156.553 \\
Agricultural film & $\mathrm{t} .10^{3} \mathrm{hm}^{-2}$ & 24.518 & 26.455 & 2.018 & 193.121 \\
Crop farming output value & $10^{8} \mathrm{Yuan}^{-1} 0^{3} \mathrm{hm}^{-2}$ & 4306.965 & 1921.234 & 808.406 & $11,697.643$ \\
Agricultural Carbon emissions & $\mathrm{t} .10^{3} \mathrm{hm}^{-2}$ & 572.579 & 271.153 & 92.292 & 2742.118 \\
\hline
\end{tabular}

Table 2. The emission coefficients of different carbon sources.

\begin{tabular}{llll}
\hline \multicolumn{1}{c}{ Carbon Source } & \multicolumn{1}{c}{ Emission Coefficient } & Units & References \\
\hline Chemical fertilizer & 0.8956 & $\mathrm{~kg} \cdot \mathrm{kg}^{-1}$ & {$[38]$} \\
Pesticides & 4.9341 & $\mathrm{~kg} \cdot \mathrm{kg}^{-1}$ & {$[39]$} \\
Agricultural film & 5.18 & $\mathrm{~kg} \cdot \mathrm{kg}^{-1}$ & {$[40]$} \\
Tillage & 312.6 & $\mathrm{~kg} \cdot \mathrm{km}^{-2}$ & {$[41]$} \\
Irrigation & 20.476 & $\mathrm{~kg} \cdot \mathrm{km}^{-2}$ & {$[42]$} \\
Agricultural machinery & 0.18 & $\mathrm{~kg} \cdot \mathrm{kW}^{-1}$ & {$[42]$} \\
\hline
\end{tabular}

\subsection{Data Sources}

The data used in this study include a balanced panel consisting of annual time series for 75 counties in Zhejiang province from 2008 to 2017, yielding 750 observations. The data for CLUE were obtained from the Statistical Yearbook of Zhejiang Province (2009-2018) [30,43] and Statistical Communique on National Economic and Social Development (2008-2017). The data for major function-oriented zones were derived from the Planning of Major Function-Oriented Zones in Zhejiang Province [31]. Fourteen counties were excluded due to data availability constraints and administrative division adjustment; more specifically, 12 counties belong to the optimized development zones, and 2 counties are owned by the key development zones. Additionally, the total area of 14 counties is $6,430.9 \mathrm{~km}^{2}$, which only accounts for $6.32 \%$ of the provincial territory.

\section{Results}

\subsection{Analysis of CLUE}

In order to analyze the impact of agricultural carbon emissions on CLUE, the SBM model that considers agricultural carbon emissions, as well as the CCR model that does not consider agricultural carbon emissions, are selected to measure the CLUE (Table 3). The mean CLUE value of the five major function-oriented zones measured by the SBM model, which considers agricultural carbon emissions, was lower when compared with the CCR model, which does not consider agricultural carbon emissions. This implies that agricultural carbon emissions have a significant negative impact on the CLUE, and not considering agricultural carbon emissions will lead to measurement bias and incorrect conclusions. Therefore, the CLUE measured by the SBM model, which considers agricultural carbon emissions, is more accurate and credible. The following section will focus on the analysis of the calculation results of the SBM model.

Within the study period, the CLUE of the five major function-oriented zones showed an increasing trend. The mean CLUE value of the optimized development, key development, agricultural production, 
ecological function, and ecological economic zone steadily increased from $0.485,0.343,0.3012,0.417$ and 0.406 in 2008 to $0.824,0.614,0.348,0.748$ and 0.688 in 2017, respectively. The average annual growth rates of CLUE in the five major function-oriented zones were $6.06 \%, 6.67 \%, 1.63 \%, 6.71 \%$ and $6.04 \%$, respectively. However, the overall level of CLUE of the five major function-oriented zones was relatively low. After ranking the CLUE value, the mean CLUE value of the optimized development zones is the highest, followed by the ecological function, ecological economic, and key development zones, and that of the agricultural production zones is the lowest, indicating that there are considerable differences in CLUE among the five major function-oriented zones. The optimized development zones have a higher level of economic development, and thus there are various funds offered by local governments with the aim to improve agricultural production conditions and technology level. However, rapid urbanization and industrialization have led to a massive land conversion from cultivated land into construction land, causing the cultivated land to become seriously scarce. Therefore, the optimized development zones paid more attention to the rational and sustainable use of cultivated land, adapted intensive use models, and ecological production behaviors in order to maximize desirable output and minimize undesirable output under the condition of relatively limited cultivated land resources. The agricultural production zones are an important grain-producing base, which has adequate cultivated land and favorable conditions for agricultural production. However, the mean CLUE value and the average annual growth rates in the agricultural production zones ranked the lowest. This implies that the CLUE under the control of major function-oriented zones is not consistent with the major function of the area, and thus the guiding role of the major function-oriented zones in CLUE needs to be strengthened. Improving the CLUE of the agricultural production zones would be a key issue in the future.

Figure 3 depicts the spatial distribution of CLUE in 2008, 2011, 2014 and 2017. According to the calculation results of CLUE, the CLUE value in each county is distributed between 0 and 1 , grading similar CLUE values into the same group is conducive to comparison [24]. Therefore, the CLUE values of this study are divided into four groups: $0-0.25,0.25-0.5,0.5-0.75$, and $0.75-1$, which are defined as low-efficiency, medium-low-efficiency, medium-high-efficiency, and high-efficiency groups, respectively. As shown in Figure 3, the number of the high-efficiency group increased from 1 in 2008 to 23 in 2017, the number of the medium-high-efficiency group increased from 16 to 27, while the number of the medium-low-efficiency group decreased from 49 to 15 . In addition, the counties with high efficiency were mainly located in the optimized development, ecological function and ecological economic zones, while the counties with low efficiency were mostly concentrated in the agricultural development and key development zones.

Table 3. The CLUE with/without considering agricultural carbon emissions.

\begin{tabular}{ccccccccccc}
\hline & $\begin{array}{c}\text { Optimized } \\
\text { Development } \\
\text { Zones }\end{array}$ & \multicolumn{2}{c}{$\begin{array}{c}\text { Key } \\
\text { Development } \\
\text { Zones }\end{array}$} & $\begin{array}{c}\text { Agricultural } \\
\text { Production } \\
\text { Zone }\end{array}$ & $\begin{array}{c}\text { Ecological } \\
\text { Function } \\
\text { Zones }\end{array}$ & $\begin{array}{c}\text { Ecological } \\
\text { Economic } \\
\text { Zones }\end{array}$ \\
\cline { 2 - 11 } & With & Without & With & Without & With & Without & With & Without & With & Without \\
\hline 2008 & 0.485 & 0.624 & 0.343 & 0.461 & 0.301 & 0.416 & 0.417 & 0.580 & 0.406 & 0.546 \\
2009 & 0.507 & 0.644 & 0.372 & 0.492 & 0.299 & 0.411 & 0.461 & 0.624 & 0.451 & 0.591 \\
2010 & 0.611 & 0.738 & 0.425 & 0.557 & 0.314 & 0.425 & 0.505 & 0.656 & 0.488 & 0.635 \\
2011 & 0.642 & 0.777 & 0.452 & 0.592 & 0.327 & 0.439 & 0.548 & 0.692 & 0.519 & 0.665 \\
2012 & 0.711 & 0.832 & 0.471 & 0.609 & 0.322 & 0.424 & 0.591 & 0.723 & 0.549 & 0.688 \\
2013 & 0.681 & 0.821 & 0.493 & 0.635 & 0.321 & 0.418 & 0.577 & 0.730 & 0.538 & 0.683 \\
2014 & 0.732 & 0.848 & 0.495 & 0.642 & 0.318 & 0.407 & 0.575 & 0.733 & 0.567 & 0.708 \\
2015 & 0.748 & 0.859 & 0.514 & 0.663 & 0.317 & 0.407 & 0.642 & 0.785 & 0.588 & 0.742 \\
2016 & 0.789 & 0.884 & 0.571 & 0.711 & 0.341 & 0.432 & 0.659 & 0.805 & 0.663 & 0.790 \\
2017 & 0.824 & 0.911 & 0.614 & 0.735 & 0.348 & 0.450 & 0.748 & 0.865 & 0.688 & 0.825 \\
mean & 0.673 & 0.794 & 0.475 & 0.610 & 0.321 & 0.423 & 0.572 & 0.719 & 0.546 & 0.687 \\
\hline
\end{tabular}




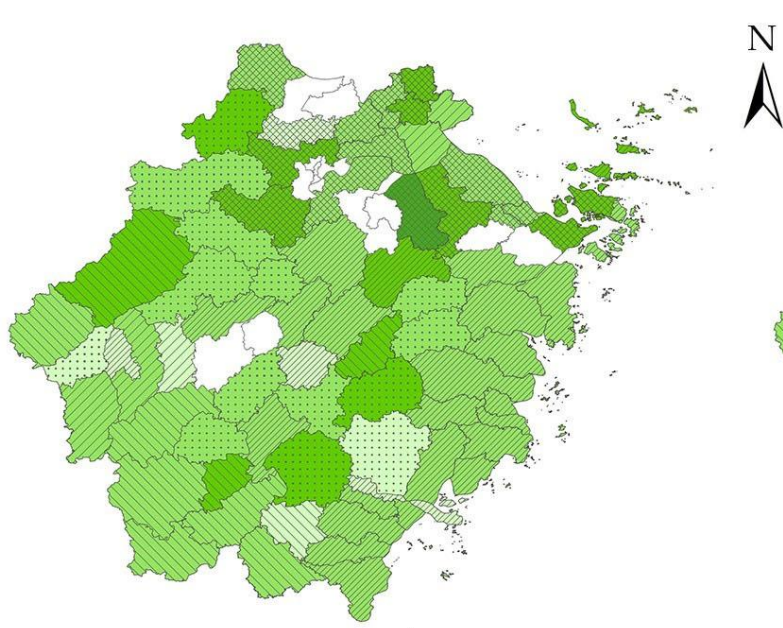

(a)

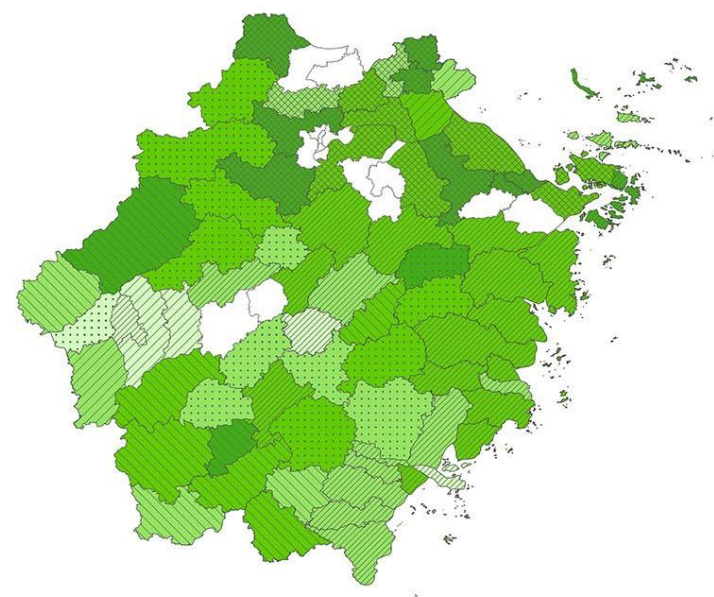

(c)

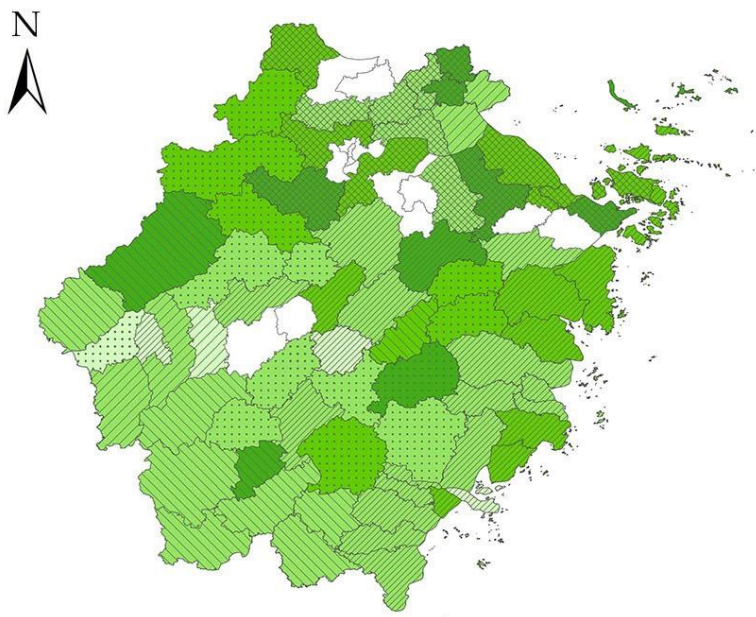

(b)

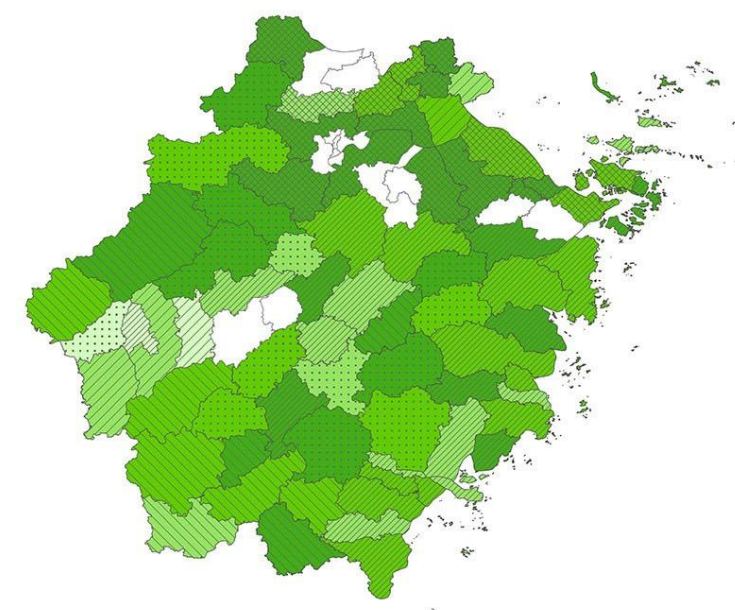

(d)

Major function-oriented zones

Optimized development zones

EA Agricultural production zones

::::: Ecological economic zones

\section{Cultivated land use efficiency}
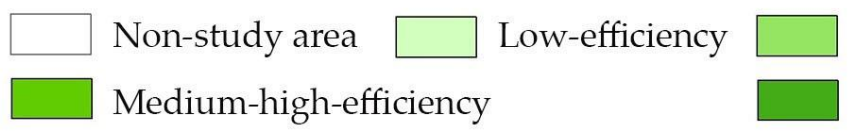

Medium-low-efficiency

High-efficiency

Figure 3. Spatial distribution of CLUE in Zhejiang province: (a) 2008; (b) 2011; (c) 2014; (d) 2017.

\subsection{Regional Disparity of CLUE}

Figure 4 illustrates the overall disparity and its decomposition of CLUE in Zhejiang province. The overall disparity of CLUE appeared to be in the form of an inverted-U shape; that is to say, the overall disparity increases first and then decreases. More specifically, the Theil index first increased from 0.0568 in 2008 to 0.0806 in 2012, and then decreased from 0.0806 in 2012 to 0.0727 in 2017. However, the Theil index in 2008 was lower than in 2017, indicating the overall movement of the trend is still upward. According to the results of the Theil index decomposition, the overall disparity of CLUE in Zhejiang province mainly comes from the within-regional disparity, and the within-regional 
disparity accounts for over $76 \%$ of the overall disparity. In contrast, the disparity among the five major function-oriented zones is relatively small, and the percentage of the overall disparity derived from between-regional disparity increased from $19.72 \%$ in 2008 to $23.28 \%$ in 2017 .

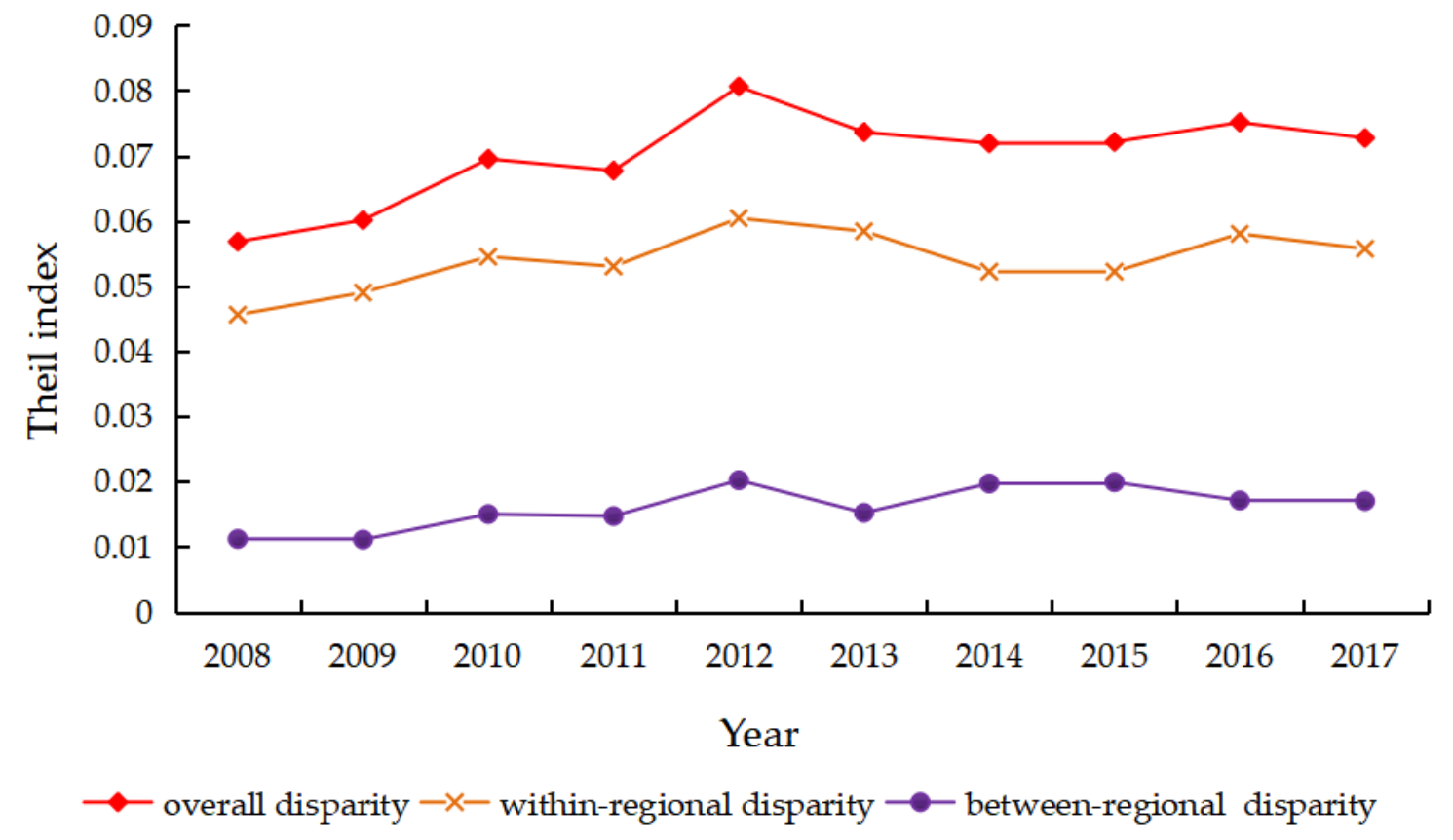

Figure 4. The regional disparity of CLUE in Zhejiang province.

In terms of the disparity within each of the major function-oriented zones (Figure 5), the within-disparity of the optimized development and ecological function zones displayed a trend of fluctuating fall, while the within-regional disparity of the key development, agricultural production, and ecological economic zones showed a trend of fluctuating increase. According to the final results, the within-regional disparity of the agricultural production zones ranked the highest, followed by the key development, ecological economic, and ecological function zones, and the optimized development zones ranked the lowest, which is contrary to the ranking of CLUE. Usually, the regional disparity of CLUE is attributed to the natural resource endowment, socioeconomic development levels, and relative scarcity of production factors [27].

From the between-regional comparison, the within-disparity of the ecological economic zones was larger than that in the other four major function-oriented zones during 2008-2010, while the within-disparity of the agricultural production zones is higher than the other four major function-oriented zones during 2010-2017, which indicates that the within-regional disparity in agricultural production zones is gradually higher than that the other four major function-oriented zones, and the within-regional disparity of CLUE in Zhejiang province mainly comes from the agricultural production zones. However, the within-regional disparity of the optimized development zones is lower than the other four major function-oriented zones during 2009-2017, which means that the optimized development zones have the highest CLUE value and average annual growth rates but the lowest within-regional disparity. 


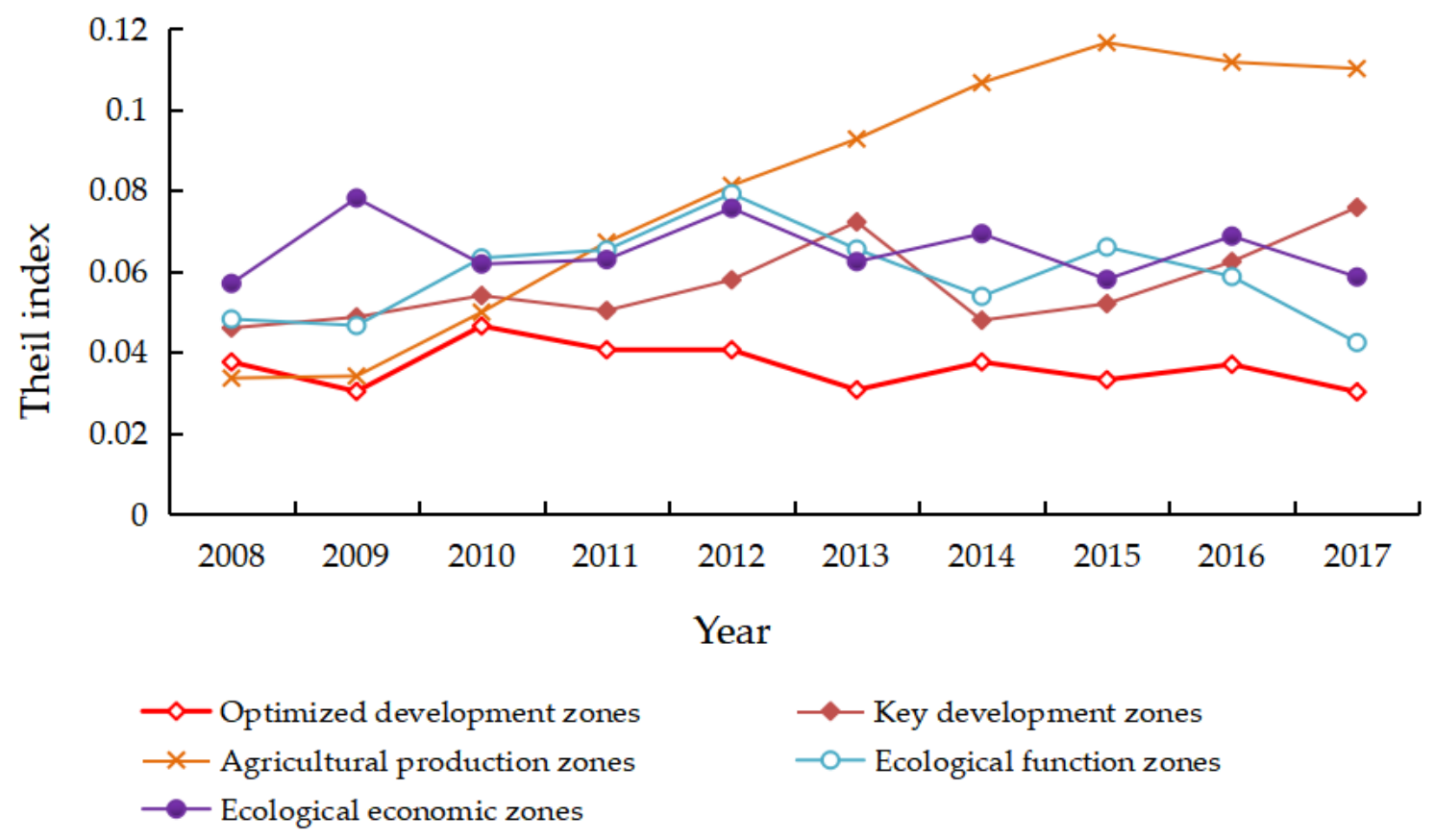

Figure 5. Within-disparity of CLUE in the five major function-oriented zones.

\subsection{Regional Convergence of CLUE}

\subsection{1. $\sigma$ Convergence of CLUE}

Figure 6 presents the standard deviation of CLUE in the five major function-oriented zones from 2008 to 2017. In general, the standard deviation of CLUE in the agricultural production zones showed a continuous upward trend, while the standard deviation of CLUE in the other four major function-oriented zones revealed a time-varying feature, instead of a consistent decrease over time. This indicates no $\sigma$ convergence in the CLUE of the five major function-oriented zones. From the perspective of inter-regional comparison, the standard deviation of the ecological economic zones is higher than that of the other four major function-oriented zones during 2008-2010; the standard deviation of the agricultural production zones is larger than that of other four major function-oriented zones during 2011-2017; and the standard deviation of optimized development zones is lower that of the other four major function-oriented zones during 2008-2017, which is fairly consistent with the result of the within-regional disparity. Besides, the coefficient of variation of CLUE in the five major function-oriented zones is featured by a temporary change, which is very similar to its standard deviation (Table 4). 

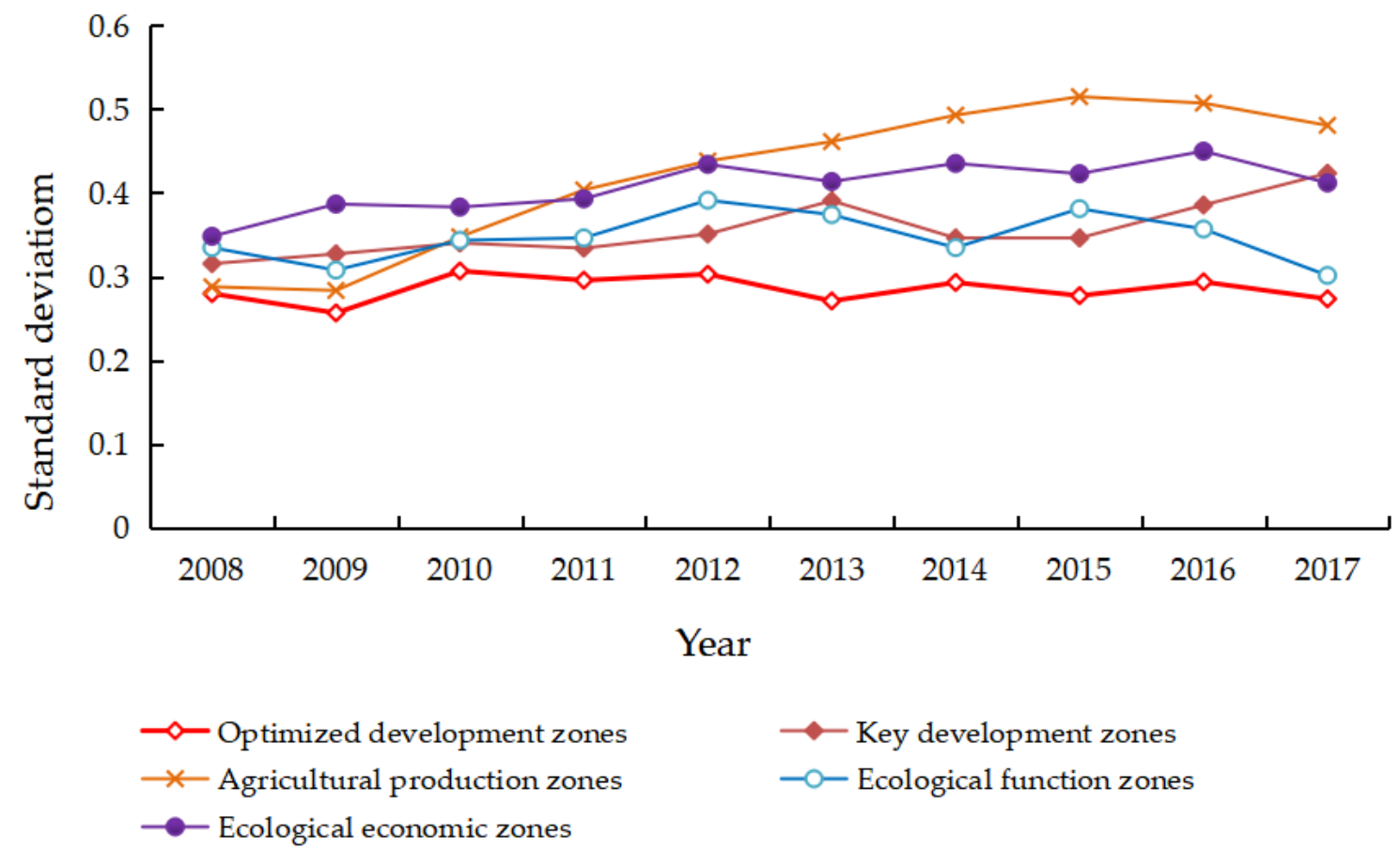

$-\circ-$ Ecological function zones

Figure 6. Standard deviation of CLUE in the five major function-oriented zones.

Table 4. Coefficient of variation of CLUE in the five major function-oriented zones.

\begin{tabular}{lllllllllll}
\hline \multicolumn{1}{c}{ Zones } & $\mathbf{2 0 0 8}$ & $\mathbf{2 0 0 9}$ & $\mathbf{2 0 1 0}$ & $\mathbf{2 0 1 1}$ & $\mathbf{2 0 1 2}$ & $\mathbf{2 0 1 3}$ & $\mathbf{2 0 1 4}$ & $\mathbf{2 0 1 5}$ & $\mathbf{2 0 1 6}$ & $\mathbf{2 0 1 7}$ \\
\hline Optimized development zones & 0.276 & 0.244 & 0.310 & 0.284 & 0.280 & 0.241 & 0.269 & 0.252 & 0.264 & 0.236 \\
Key development zones & 0.303 & 0.311 & 0.330 & 0.316 & 0.346 & 0.390 & 0.300 & 0.300 & 0.349 & 0.385 \\
Agricultural production zones & 0.249 & 0.253 & 0.307 & 0.357 & 0.396 & 0.427 & 0.460 & 0.484 & 0.488 & 0.447 \\
Ecological function zones & 0.305 & 0.309 & 0.367 & 0.375 & 0.408 & 0.362 & 0.331 & 0.362 & 0.342 & 0.289 \\
Ecological economic zones & 0.339 & 0.416 & 0.347 & 0.349 & 0.384 & 0.339 & 0.361 & 0.319 & 0.353 & 0.326 \\
\hline
\end{tabular}

\subsubsection{Absolute $\beta$ Convergence of CLUE}

Table 5 reports the absolute $\beta$ convergence test result of CLUE in the five major function-oriented zones. The parameter $\beta$ of the optimized development zones in the two time periods were negative, but neither reaches the significance test. This means that the optimized development zones showed a trend of absolute $\beta$ convergences, but this trend was not significant. The parameter $\beta$ of the agricultural production zones in the two time periods were positive, but neither reached the significance test, which indicates that no absolute $\beta$ convergence occurs in the agricultural production zones. The parameter $\beta$ of the key development and ecological economic zones were positive in the first period and negative in the second period, but neither reached the significance test. This means that no absolute $\beta$ convergence occurs in the two major function-oriented zones during 2008-2012, while absolute $\beta$ convergence occurs during 2013-2017, although not significant.

The parameter $\beta$ of the ecological function zones in the two time periods were negative. However, the parameter $\beta$ in the first period does not reach the significance test, while it is significant in the second period. This implies that the ecological function zones show a significant trend of absolute $\beta$ convergence during 2013-2017, but there is no convincing statistical evidence in favor of absolute $\beta$ convergence during 2008-2012. There is a catch-up effect for the counties in the ecological function zones with lower CLUE to that with higher CLUE. Meanwhile, the convergence $\lambda$ of the two time periods is $1.29 \%$ and $11.68 \%$, respectively, which means that the within-regional CLUE will gradually converge to the same steady-state level at different convergence rates in different periods. However, 
combining with the results of the two time periods, no significant $\beta$ convergence occurs in the ecological function zones.

It can be concluded that there is no convincing statistical evidence in favor of absolute $\beta$ convergence in the five major function-oriented zones; that is, due to the presence of multidimensional heterogeneity, the CLUE in the five major function-oriented zones will not reach the same steady-state level. Given the importance of CLUE growth in economic development, food security, and ecologic protection, it is essential to develop specific-regional planning to stimulate the "catch-up" effect of the CLUE.

Table 5. Estimation results of the absolute $\beta$ convergence test.

\begin{tabular}{lllllllll}
\hline \multirow{2}{*}{ Zones } & \multicolumn{3}{c}{ 2008-2012 } & \multicolumn{5}{c}{ 2013-2017 } \\
\cline { 2 - 9 } & \multicolumn{1}{c}{$\boldsymbol{\beta}$} & R-squared & $\lambda$ & $\theta$ & $\boldsymbol{R}$ & R-squared & $\lambda$ & $\theta$ \\
\hline Optimized development zones & $\begin{array}{l}-0.093 \\
(0.075)\end{array}$ & 0.151 & 0.117 & 5.952 & $\begin{array}{l}-0.041 \\
(0.028)\end{array}$ & 0.077 & 0.044 & 15.603 \\
\hline Key development zones & $\begin{array}{l}0.005 \\
(0.030)\end{array}$ & 0.002 & - & - & $\begin{array}{l}-0.016 \\
(0.033)\end{array}$ & 0.014 & 0.017 & 40.863 \\
\hline Agricultural production zones & $\begin{array}{l}0.103 \\
(0.056)\end{array}$ & 0.344 & - & - & $\begin{array}{l}0.005 \\
(0.012)\end{array}$ & 0.010 & - & - \\
\hline Ecological function zones & $\begin{array}{l}-0.013 \\
(0.054)\end{array}$ & 0.006 & 0.013 & 53.613 & $\begin{array}{l}-0.093 \\
(0.038)\end{array}$ & 0.352 & 0.117 & 5.935 \\
\hline Ecological economic zones & $\begin{array}{l}0.029 \\
(0.042)\end{array}$ & 0.040 & - & - & $\begin{array}{l}-0.013 \\
(0.024)\end{array}$ & 0.028 & 0.013 & 52.754 \\
\hline
\end{tabular}

Note: Robust standard errors in parentheses; ${ }^{* *}$ significant at $5 \%$, level.

\subsubsection{Conditional $\beta$ Convergence of CLUE}

Table 6 provides the conditional $\beta$ convergence test results of CLUE in the five major function-oriented zones. The parameter $\beta$ of the optimized development, key development, and ecological economic zones in the two time periods were significantly negative. These results imply that conditional $\beta$ convergence occurs in the CLUE of the three major function-oriented zones, and the CLUE of each county in the three major function-oriented zones will converge to its respective steady-state level at different convergence rates in different periods. However, a slower convergence rate does not indicate a lower CLUE level, counties with lower CLUE in the beginning may grow higher or faster than others.

The parameter $\beta$ of the agricultural production zones at the two time periods was 0.002 and -0.632 , respectively, but neither reaches statistical significance. This indicates that no conditional $\beta$ convergence occurs in the agricultural production zones during 2008-2012, while conditional $\beta$ convergence occurs during 2013-2017, although not significant. The parameter $\beta$ of the ecological function zones in the two time periods was -0.367 and -1.247 , respectively. Although the parameter $\beta$ in the second period was significant at the $1 \%$ level, when the parameter was substituted into the formula (13), it was unable to calculate the convergence rate. No conditional $\beta$ convergence occurs in the agricultural production and ecological function zones, which further implied that the CLUE in the two major function-oriented zones does not converge towards its respective steady-state level. With the effort of local governments and the support of national policies, the CLUE in the two major function-oriented zones has greatly improved. However, the cultivated land use in the two major function-oriented zones is still extensive rather than intensive, and thus the model of cultivated land intensive use based on efficiency has not played a dominant role. To put it simply, the CLUE in the agricultural production and ecological function zones have not yet been mature, which makes them fail to find suitable convergence paths.

It can be concluded that the optimized development, key development, and ecological economic zones showed significant evidence of conditional $\beta$ convergence in two periods, 2008-2012 and 2013-2017. The CLUE in the three major function-oriented zones will converge to its respective 
steady-state level. However, there is no convincing statistical evidence in favor of conditional $\beta$ convergence in the agricultural production and ecological function zones.

Table 6. Estimation results of the conditional $\beta$ convergence test.

\begin{tabular}{llllllllll}
\hline \multicolumn{1}{c}{ Zones } & \multicolumn{3}{c}{ 2008-2012 } & \multicolumn{3}{c}{ 2013-2017 } \\
\cline { 2 - 9 } & \multicolumn{1}{c}{$\boldsymbol{\beta}$} & $\mathbf{R}$-squared & $\lambda$ & $\boldsymbol{\tau}$ & $\beta$ & R-squared & $\lambda$ & $\boldsymbol{\tau}$ \\
\hline Optimized development zones & $\begin{array}{l}-0.810^{* * *} \\
(0.098)\end{array}$ & 0.586 & 0.415 & 1.668 & $\begin{array}{l}-0.928^{* * *} \\
(0.191)\end{array}$ & 0.322 & 0.659 & 1.052 \\
\hline Key development zones & $\begin{array}{l}-0.558^{* * *} \\
(0.120)\end{array}$ & 0.494 & 0.204 & 3.399 & $\begin{array}{l}-0.632^{* * *} \\
(0.162)\end{array}$ & 0.407 & 0.250 & 2.771 \\
\hline Agricultural production zones & $\begin{array}{l}0.002 \\
(0.063)\end{array}$ & 0.290 & - & - & $\begin{array}{l}-0.632 \\
(0.298)\end{array}$ & 0.697 & 0.250 & 2.774 \\
\hline Ecological function zones & $\begin{array}{l}-0.367 \\
(0.237)\end{array}$ & 0.192 & 0.114 & 6.063 & $\begin{array}{l}-1.247^{* * *} \\
(0.262)\end{array}$ & 0.506 & - & - \\
\hline Ecological economic zones & $\begin{array}{l}-0.763^{* * *} \\
(0.204)\end{array}$ & 0.521 & 0.360 & 1.928 & $\begin{array}{l}-0.545^{* * *} \\
(0.107)\end{array}$ & 0.319 & 0.197 & 3.526 \\
\hline
\end{tabular}

Note: Robust standard errors in parentheses; ${ }^{* * *}$ significant at $1 \%$ level.

\section{Discussion}

\subsection{Does CLUE Match the Functional Positioning of the Major Function-Oriented Zones?}

The planning of major function-oriented zones is the guideline for optimizing the spatial pattern of land development in China, and regional functional positioning has an important influence on CLUE. Previous studies on CLUE were mainly limited to national, provincial or basin scales [14,23,25-29]; almost no studies have quantitatively evaluated and analyzed the CLUE in various major function-oriented zones. Taking Zhejiang province as a research case, this study linked the planning of major function-oriented zones when evaluating the degree of cultivated land use, matched the CLUE with the function positioning of various major function-oriented zones, and completed the evaluation of the CLUE by the matching degree. Based on the calculation result, the CLUE value of the optimized development zones was the highest, followed by the ecological function, ecological economic, and key development zones. The agricultural production zones gave the lowest CLUE value. These indicate that the major function-oriented zones reflect the regional disparity of CLUE to some extent. However, the CLUE under the control of major function-oriented zones is not consistent with the function positioning.

While the agricultural production zones have adequate cultivated land and favorable conditions for agricultural production, their CLUE ranked the lowest, which does not match their functional positioning to "guarantee the effective supply of agricultural products". The agricultural production zones should pay attention to the sustainable use of cultivated land while pursuing high-yield grain production, improve agricultural production conditions, and strengthen the prevention and control of agricultural carbon emissions.

The ecological function and ecological economic zones have strong ecological sensitivity, low resource and environmental carrying capacity, and they do not have the conditions for large-scale, high-intensity agricultural cultivation, but their CLUE were ranked second and third, respectively, which does not match their functional positioning of "restricted development". It is necessary for the two major function-oriented zones to take agricultural development, ecological construction, and environmental protection as important tasks, and vigorously carry out soil and water conservation projects and farmland water conservancy projects. They should earnestly protect the cultivated land and increase the agricultural comprehensive production capacity to ensure the security of agricultural product supply, and strengthen the construction of the ecological environment to enhance the functions of soil and water conservation and biodiversity maintenance, ultimately increasing the supply capacity of ecological products. 
Although the CLUE in the optimized development zones is closer to the production frontier, rapid industrialization and urbanization have made the construction land seriously scarce, causing the opportunity cost of agricultural production to be relatively high. Therefore, the optimized development zones should strictly protect basic farmland and control the occupation of cultivated land for non-agricultural purposes. Meanwhile, the CLUE of the agricultural production zones is relatively low, and more cultivated land needs to be consolidated and developed. The cross-regional reallocation of cultivated land resources should be allowed on the premise of ensuring the dynamic balance of the total cultivated land; that is, the agricultural production zones can sell more construction land indicators to the optimized development zones in exchange for sufficient funds for cultivated land consolidation and agricultural infrastructure investment.

\subsection{Limitations and Future Directions}

This study focused on the quantitative characterization of CLUE change in various major function-oriented zones. Therefore, this study only selected the direct factors (i.e., input, desirable output, and undesirable output indicators) that determine the CLUE, and did not further analyze the hidden factors such as cultivated land quality, cultivated land fragmentation, crop planting structure, economic development level, or other policy variables. Subsequent research would focus on the analysis of the driving factors that affect the CLUE in various major function-oriented zones. Agricultural diesel consumption is one of the key input indicators and an important source of agricultural carbon emissions, but the Statistical Bureau of Zhejiang Province has not reported the data pertaining to the agricultural diesel consumption. Also, this study does not consider agricultural diesel consumption when constructing the indicator system of CLUE due to the limitation of data collection. Incomplete indicators caused biased estimation of CLUE, though it is a common weakness of empirical studies [25-29,44]. Moreover, the evaluation of CLUE is only one aspect of land use. Research related to land use (e.g., land use carbon budget and compensation, urban land or built-up land use eco-efficiency) other than CLUE can be carried out based on the planning of major function-oriented zones.

\section{Conclusions}

We included agricultural carbon emission into the indicator system of CLUE, then the SBM model was selected to measure the CLUE of Zhejiang province and its five major function-oriented zones from 2008 to 2017. Based on the calculation results, the Theil index and convergence theory were adopted to analyze the regional disparity and convergence of CLUE in various major function-oriented zones and different periods. The main conclusions are summarized as follows.

Compared with the CCR model, which did not consider agricultural carbon emissions, the measurement result of the SBM model, which considered agricultural carbon emissions, was lower. This indicates that agricultural carbon emissions have a significant negative impact on the CLUE.

The CLUE of the five major function-oriented zones showed varying degrees of increases. After ranking the CLUE value, the CLUE value of the optimized development zones is the highest, followed by the ecological function, ecological economic, and key development zones, and that of the agricultural development zones is the lowest. This implies there are significant differences in CLUE among various major function-oriented zones, but the CLUE under the control of major function-oriented zones is not consistent with the function positioning.

The overall disparity of CLUE presented an upward trend, and the within-regional disparity is the main source of the overall disparity. Besides, the within-regional disparity in CLUE of the agricultural development zones was the highest, and that of the optimized development zones was the lowest, which was contrary to the ranking of CLUE.

Standard deviation and coefficient of variation were employed to examine whether the deviation of CLUE within each major function-oriented zone tends to decrease over time. The standard deviation of CLUE in the five major function-oriented zones displayed a time-varying trend, instead of a consistent decrease over time, indicating that no $\sigma$ convergence occurs in the five major function-oriented zones. 
The coefficient of variation was adopted to carry out the robustness test, which confirmed the reliability of the main results.

There was no absolute $\beta$ convergence in the CLUE of the five major function-oriented zones, but there was significant conditional $\beta$ convergence in the optimized development, key development, and ecological function zones. Also, the convergence rate and convergence time were different in the three major function-oriented zones. This implies that the CLUE in the five major function-oriented zones will not reach the same steady-state level due to the presence of heterogeneity. However, the CLUE in the optimized development, key development, and ecological function zones will converge to its respective steady-state level conditional on region-specific characteristics.

Author Contributions: Conceptualization, C.Z. and G.Y.; methodology, C.Z. and D.C.; software, C.Z., D.C. and R.Y.; validation, C.Z., G.Y. and Y.S.; former analysis, C.Z., G.Y. and Y.S.; data curation, C.Z., D.C. and Y.S.; writing—original draft preparation, C.Z. and G.Y.; writing-review and editing, C.Z., G.Y. and Y.S.; visualization, C.Z., D.C., Y.S. and R.Y; funding acquisition, G.Y. All authors have read and agreed to the published version of the manuscript.

Funding: This research was funded by the National Natural Science Foundation of China, grant number 41801190; the Humanities and Social Sciences Foundation of the Ministry of Education of China, grant number 15YJC790013.

Acknowledgments: We are thankful to Yulong Li (native English speaker) for English language editing. We also extend great gratitude to the anonymous reviewers and editors for their helpful reviews and critical comments.

Conflicts of Interest: The authors declare no conflict of interest.

\section{Appendix A}

Table A1. Description of the five major function-oriented zones.

\begin{tabular}{|c|c|c|c|}
\hline Zones & Zones Characteristics & Function Positioning & Major Function \\
\hline $\begin{array}{c}\text { Optimized development } \\
\text { zones }\end{array}$ & $\begin{array}{c}\text { More developed economy; } \\
\text { High development intensity; } \\
\text { High population density; } \\
\text { Severe resource and environmental } \\
\text { problems. }\end{array}$ & $\begin{array}{l}\text { Promote regional competitiveness; } \\
\text { Lead economic and social } \\
\text { development; } \\
\text { Increase population and economy } \\
\text { agglomeration. }\end{array}$ & $\begin{array}{l}\text { Provide industrial } \\
\text { products and service }\end{array}$ \\
\hline Key development zones & $\begin{array}{c}\text { Certain economic foundation; } \\
\text { High development potential; } \\
\text { High resource and environmental } \\
\text { carrying capacity; } \\
\text { Favorable conditions for population } \\
\text { agglomeration and economic } \\
\text { development. }\end{array}$ & $\begin{array}{c}\text { Support sustained economic } \\
\text { development; } \\
\text { Undertake population and industrial } \\
\text { transfer; } \\
\text { Develop a modern industry and } \\
\text { marine economy. }\end{array}$ & $\begin{array}{l}\text { Provide industrial } \\
\text { products and service }\end{array}$ \\
\hline $\begin{array}{l}\text { Agricultural production } \\
\text { zones }\end{array}$ & $\begin{array}{l}\text { Adequate cultivated land; } \\
\text { Favorable conditions for agricultural } \\
\text { production. }\end{array}$ & $\begin{array}{l}\text { Build new socialist countryside; } \\
\text { farmer live and work in peace and } \\
\text { contentment; } \\
\text { Guarantee the effective supply of } \\
\text { agricultural products. }\end{array}$ & $\begin{array}{l}\text { Provide agricultural } \\
\text { products }\end{array}$ \\
\hline Ecological function zones & $\begin{array}{l}\text { Fragile ecosystem or strong } \\
\text { ecological sensitivity; } \\
\text { Low resource and environmental } \\
\text { carrying capacity. }\end{array}$ & $\begin{array}{c}\text { Safeguard the ecological safety; } \\
\text { Provide a variety of ecological } \\
\text { services. }\end{array}$ & $\begin{array}{l}\text { Provide ecological } \\
\text { products }\end{array}$ \\
\hline $\begin{array}{c}\text { Ecological economic } \\
\text { zones }\end{array}$ & $\begin{array}{l}\text { Ecological service function is more } \\
\text { important; } \\
\text { Certain resource and environmental } \\
\text { carrying capacity. }\end{array}$ & $\begin{array}{l}\text { Develop ecological economy; } \\
\text { Promote urbanization and } \\
\text { industrialization moderately; } \\
\text { Guarantee the supply of agricultural } \\
\text { and ecological products. }\end{array}$ & $\begin{array}{l}\text { Provide ecological and } \\
\text { cultural products }\end{array}$ \\
\hline $\begin{array}{l}\text { Forbidden development } \\
\text { zones }\end{array}$ & $\begin{array}{l}\text { Industrial is prohibited; } \\
\text { Ecological areas require special } \\
\text { protection; } \\
\text { Natural and cultural preserves } \\
\text { established by law. }\end{array}$ & $\begin{array}{l}\text { Inherit history and culture; } \\
\text { Protect natural resources and } \\
\text { ecological environment. }\end{array}$ & $\begin{array}{c}\text { Provide agricultural, } \\
\text { ecological, and cultural } \\
\text { products }\end{array}$ \\
\hline
\end{tabular}


Table A2. Standard deviation of CLUE in the five major function-oriented zones.

\begin{tabular}{lcccccccccc}
\hline \multicolumn{1}{c}{ Zones } & $\mathbf{2 0 0 8}$ & $\mathbf{2 0 0 9}$ & $\mathbf{2 0 1 0}$ & $\mathbf{2 0 1 1}$ & $\mathbf{2 0 1 2}$ & $\mathbf{2 0 1 3}$ & $\mathbf{2 0 1 4}$ & $\mathbf{2 0 1 5}$ & $\mathbf{2 0 1 6}$ & $\mathbf{2 0 1 7}$ \\
\hline Optimized development zones & 0.280 & 0.257 & 0.307 & 0.296 & 0.303 & 0.271 & 0.293 & 0.277 & 0.294 & 0.273 \\
Key development zones & 0.315 & 0.327 & 0.340 & 0.334 & 0.351 & 0.391 & 0.346 & 0.346 & 0.385 & 0.423 \\
Agricultural production zones & 0.288 & 0.283 & 0.347 & 0.403 & 0.438 & 0.461 & 0.493 & 0.515 & 0.507 & 0.481 \\
Ecological function zones & 0.335 & 0.308 & 0.343 & 0.346 & 0.391 & 0.374 & 0.335 & 0.381 & 0.357 & 0.301 \\
Ecological economic zones & 0.348 & 0.387 & 0.383 & 0.393 & 0.434 & 0.414 & 0.435 & 0.423 & 0.450 & 0.412 \\
\hline
\end{tabular}

Table A3. Regional disparity of CLUE in Zhejiang province and its five major function-oriented zones.

\begin{tabular}{ccccccccccc}
\hline & $\mathbf{2 0 0 8}$ & $\mathbf{2 0 0 9}$ & $\mathbf{2 0 1 0}$ & $\mathbf{2 0 1 1}$ & $\mathbf{2 0 1 2}$ & $\mathbf{2 0 1 3}$ & $\mathbf{2 0 1 4}$ & $\mathbf{2 0 1 5}$ & $\mathbf{2 0 1 6}$ & $\mathbf{2 0 1 7}$ \\
\hline Optimized development zones & 0.038 & 0.030 & 0.047 & 0.041 & 0.041 & 0.031 & 0.038 & 0.033 & 0.037 & 0.030 \\
Key development zones & 0.046 & 0.049 & 0.054 & 0.050 & 0.058 & 0.072 & 0.048 & 0.052 & 0.062 & 0.076 \\
Agricultural production zones & 0.034 & 0.034 & 0.050 & 0.067 & 0.081 & 0.093 & 0.107 & 0.117 & 0.112 & 0.110 \\
Ecological function zones & 0.048 & 0.047 & 0.063 & 0.065 & 0.079 & 0.066 & 0.054 & 0.066 & 0.059 & 0.042 \\
Ecological economic zones & 0.057 & 0.078 & 0.062 & 0.063 & 0.076 & 0.062 & 0.069 & 0.058 & 0.069 & 0.059 \\
Theil within $_{\text {Theil }}$ & 0.046 & 0.049 & 0.055 & 0.053 & 0.06 & 0.058 & 0.052 & 0.052 & 0.058 & 0.056 \\
Theil $_{\text {overall }}$ & 0.011 & 0.011 & 0.015 & 0.015 & 0.020 & 0.015 & 0.020 & 0.020 & 0.017 & 0.017 \\
& 0.057 & 0.060 & 0.070 & 0.068 & 0.081 & 0.074 & 0.072 & 0.072 & 0.075 & 0.073 \\
\hline
\end{tabular}

\section{References}

1. State Council of China. The National Plan for Major Function-Oriented Zones. Available online: http: //www.gov.cn/zhengce/content/2011-06/08/content_1441.htm (accessed on 21 December 2010).

2. Wang, W.X.; Wang, W.J.; Xie, P.C.; Zhao, D.Q. Spatial and temporal disparities of carbon emissions and interregional carbon compensation in major function-oriented zones: A case study of Guangdong province. J. Clean. Prod. 2020, 245, 118873. [CrossRef]

3. Liu, W.C.; Liu, J.Y.; Kuang, W.H.; Ning, J. Examining the influence of the implementation of major function-oriented zones on built-up area expansion in China. J. Geogr. Sci. 2017, 27, 643-660. [CrossRef]

4. Wu, D.; Zou, C.X.; Cao, W.; Liu, L.L. Analysis of the ecosystem soil conservation function based on the major function-oriented zones across the Yangtze River Economic Belt, China. Sustainability 2018, 10, 3425. [CrossRef]

5. Su, M.; Guo, R.Z.; Hong, W.Y. Institutional transition and implementation path for cultivated land protection in highly urbanized regions: A case study of Shenzhen, China. Land Use Policy 2019, 81, 493-501. [CrossRef]

6. Janus, J.; Bozek, P. Land abandonment in Poland after the collapse of socialism: Over a quarter of a century of increasing tree cover on agricultural land. Ecol. Eng. 2019, 138, 106-117. [CrossRef]

7. Deng, X.Z.; Gibson, J.; Wang, P. Management of trade-offs between cultivated land conversions and land productivity in Shandong province. J. Clean. Prod. 2017, 142, 767-774. [CrossRef]

8. Zhou, Y.; Guo, L.Y.; Liu, Y.S. Land consolidation boosting poverty alleviation in China: Theory and practice. Land Use Policy. 2019, 82, 339-348. [CrossRef]

9. Ciaian, P.; Guri, F.; Rajcaniova, M.; Drabik, D.; Paloma, S.G.Y. Land fragmentation and production diversification: A case study from rural Albania. Land Use Policy 2018, 76, 589-599. [CrossRef]

10. Lu, X.H.; Kuang, B.; Li, J. Regional difference decomposition and policy implications of China's urban land use efficiency under the environmental restriction. Habitat Int. 2018, 77, 32-39. [CrossRef]

11. Xie, H.L.; Chen, Q.R.; Lu, F.C.; Wang, W.; Yao, G.R.; Yu, J.L. Spatial-temporal disparities and influencing factors of total-factor green use efficiency of industrial land in China. J. Clean. Prod. 2019, 207, 1047-1058. [CrossRef]

12. Li, H.; Zhang, X.L.; Zhang, X.; Wu, Y.Z. Utilization benefit of cultivated land and land institution reforms: Economy, society and ecology. Habitat. Int. 2018, 77, 64-70. [CrossRef]

13. Reddy, N.B.K.; Ramanaiah, Y.V. Changes in agricultural land use efficiency in Andhra Pradesh: A study by the Standard Coefficient method. Land Use Policy 1985, 6, 210-216. [CrossRef]

14. Han, H.; Zhang, X. Static and dynamic cultivated land use efficiency in China: A minimum distance to strong efficient frontier approach. J. Clean. Prod. 2019, 246, 119002. [CrossRef]

15. Deng, X.Z.; Huang, J.K.; Rozelle, S.; Uchida, E. Cultivated land conversion and potential agricultural productivity in China. Land Use Policy 2006, 23, 372-384. [CrossRef] 
16. Y, Y.; Stomph, T.J.; Makowski, D.; Werf, W.V.D. Temporal niche differentiation increases the land equivalent ratio of annual intercrops: A meta-analysis. Field Crops Res. 2015, 184, 133-144.

17. Xiang, M.T.; Yu, Q.Y.; Wu, W.B. From multiple cropping index to multiple cropping frequency: Observing cropland use intensity at a finer scale. Ecol. Indic. 2019, 101, 892-903. [CrossRef]

18. Hiebesch, C.K.; McCollum, R.E. Area $\times$ time equivalency ratio: A method for evaluating the productivity of intercrops. Agron. J. 1987, 79, 15-22. [CrossRef]

19. Yang, C.H.; Wu, L.; Lin, H.L. Analysis of total-factor cultivated land efficiency in China's agriculture. Agric. Econ. 2010, 56, 231-242.

20. Charnes, A.; Cooper, W.W. Measuring the efficiency of decision making units. Eur. J. Oper. Res. 1978, 2, 429-444. [CrossRef]

21. Tone, K. Dealing with Undesirable Outputs in DEA: A slacks-based measure (SBM) approach. In Proceedings of the North American Productivity Workshop, Toronto, ON, Canada, 23-25 June 2004; pp. 44-45.

22. Tone, K. A slacks-based measure of efficiency in data envelopment analysis. Eur. J. Oper. Res. 2001, 130, 498-509. [CrossRef]

23. Xie, H.L.; Chen, Q.R.; Wang, W.; He, Y.F. Analyzing the green efficiency of arable land use in china. Technol. Forecast. Soc. Chang. 2018, 133, 15-28. [CrossRef]

24. Han, H.B.; Zhong, Z.Q.; Wen, C.C.; Sun, H.G. Agricultural environmental total factor productivity in China under technological heterogeneity: Characteristics and determinants. Environ. Sci. Pollut. Res. 2018, 25, 32096-32111. [CrossRef]

25. Chen, Q.R.; Xie, H.L. Temporal-spatial differentiation and optimization analysis of cultivated land green utilization efficiency in China. Land 2019, 8, 158. [CrossRef]

26. Hou, X.H.; Liu, J.M.; Zhang, D.J.; Zhao, M.J.; Xia, C.Y. Impact of urbanization on the eco-efficiency of cultivated land utilization: A case study on the Yangtze River Economic Belt, China. J. Clean Prod. 2019, 238, 117916. [CrossRef]

27. Kuang, B.; Lu, X.H.; Zhou, M.; Chen, D.L. Provincial cultivated land use efficiency in China: Empirical analysis based on the SBM-DEA model with carbon emissions considered. Technol. Forecast. Soc. Chang. 2020, 151, 119874. [CrossRef]

28. Xie, H.L.; Chen, Q.R.; Choi, Y.R. Measuring the cultivated land use efficiency of the main grain-producing areas in China under the constraints of carbon emissions and agricultural non-point source pollution. Sustainability 2018, 10, 1932. [CrossRef]

29. Qiu, L.F.; Zhu, J.X.; Pan, Y.; Wu, S.H.; Dang, Y.X.; Xu, B.G.; Yang, H. The positive impacts of landscape fragmentation on the diversification of agricultural production in Zhejiang Province, China. J. Clean. Prod. 2020, 251, 119722. [CrossRef]

30. Statistical Bureau of Zhejiang Province, Survey Office of the National Bureau of Statistics in Zhejiang. Zhejiang Statistical Yearbook 2018; China Statistics Press: Beijing, China, 2018.

31. People's Government of Zhejiang Province. The Planning of the Major Function-Oriented Zones in Zhejiang Province. Available online: http://jz.docin.com/p-732612115.html (accessed on 29 November 2013).

32. Theil, H. World Income Inequality and its Components. Econ. Lett. 1979, 2, 99-102. [CrossRef]

33. Chen, Z.H.; Haynes, K.E. Impact of high-speed rail on regional economic disparity in China. J. Transp. Geogr. 2017, 65, 80-91. [CrossRef]

34. $\mathrm{Lu}, \mathrm{X} . ; \mathrm{Xu}, \mathrm{C} . \mathrm{X}$. The difference and convergence of total factor productivity of inter-provincial water resources in China based on three- stage DEA-Malmquist index model. Sustain. Comput.-Inform. 2019, 22, 75-83. [CrossRef]

35. Barro, R.J.; Sala-I-Martin, X. Convergence across states and regions. Brook. Pap. Econ. Act. 1991, 22, $107-182$. [CrossRef]

36. Islam, N. What have we learnt from the convergence debate? J. Econ. Surv. 2003, 17, 309-362. [CrossRef]

37. Miller, S.M.; Upadhyay, M.P. Total factor productivity and the convergence hypothesis. J. Macroecon. 2002, 24, 267-286. [CrossRef]

38. West, T.O.; Marland, G.A. Synthesis of carbon sequestration, carbon emissions, and net carbon flux in agriculture: Comparing tillage practices in the United States. Agric. Ecosyst. Environ. 2002, 91, 217-232. [CrossRef]

39. Post, W.M.; Kwon, K.C. Soil carbon sequestration and land use change: Processes and potential. Glob. Chang. Biol. 2000, 6, 317-327. [CrossRef] 
40. Institute of Resource, Ecosystem and Environment of Agriculture in Nanjing Agricultural University. Available online: http://ireea.njau.edu.cn/ch/DownShow.asp?ID=101 (accessed on 5 November 2007).

41. Wu, F.L.; Li, L.; Zhang, H.L.; Chen, F. Effects of conservation tillage on net carbon flux from farmland ecosystems. Chin. J. Eco. 2007, 26, 2035-2039. (In Chinese)

42. Li, J.J. Research on characteristics and driving factors of agricultural land carbon emission in provinces of minorities in China. China Popul. Resour. Environ. 2012, 22, 42-47. (In Chinese)

43. Statistical Bureau of Zhejiang Province, Survey Office of the National Bureau of Statistics in Zhejiang. Zhejiang Statistical Yearbook; China Statistics Press: Beijing, China, 2009-2017.

44. Zhang, J.R.; Zeng, W.H.; Wang, J.N.; Yang, F.L.; Jiang, H.Q. Regional low-carbon economy efficiency in China: Analysis based on the Super-SBM model with CO2 Emiss. J. Clean. Prod. 2017, 163, 202-211. [CrossRef]

(C) 2020 by the authors. Licensee MDPI, Basel, Switzerland. This article is an open access article distributed under the terms and conditions of the Creative Commons Attribution (CC BY) license (http://creativecommons.org/licenses/by/4.0/). 